\title{
REDUCING CONSTRUCTION LOGISTICS COSTS AND EMBODIED CARBON WITH CCC AND KITTING: A CASE STUDY
}

\author{
Fabrice Berroir ${ }^{1}$, Pierre Guernaccini², Calin Boje ${ }^{3}$, and Omar Maatar ${ }^{4}$
}

\begin{abstract}
Supply chain management was originally proposed to improve construction sites performances, nonetheless this simultaneously presents a potential solution for reducing the carbon footprint of the construction sector. Therefore, both environmental and cost impacts must be considered in order to raise the sector's awareness and foster change towards more sustainable practices. The purpose of this research is to evaluate the applicability of such a model for the supply chain by implementing Just-in-Time deliveries using kitting and a Construction Consolidation Centre managed by a ThirdParty Logistics operator on a real-life construction project. Data was collected on actual tasks durations, time losses for site's workers and deliveries, and used as input to estimate the corresponding values with a traditional logistics and to model impact on both direct and indirect costs for comparison and discussion. Findings indicate that this new logistics paradigm can lead to productivity improvements and overall reduction in transportation needs. These have an implicit positive impact on both the environment and cost savings, which are calculated and discussed. Based on these results, it is argued that the adoption of this model contributes to a lean-green deal by demonstrating the positive impact of Lean Construction techniques towards better supply chain integration.
\end{abstract}

\section{KEYWORDS}

Supply chain management (SCM), sustainability, action research, CCC, kitting.

\section{INTRODUCTION}

From a supply chain perspective, a construction project can be viewed as an assembly process that requires several types of materials or components to be put together. As a result, activities such as the purchasing of materials and services from suppliers and subcontractors represent between 60 and $80 \%$ of the gross work done in construction projects, which consequently have an important impact on project performance (Eleskar 2020). Applying adequate logistics methods is still a major challenge as these are often poorly mastered or sometimes even consciously neglected when it comes to cutting costs.

1 R\&D Engineer, Luxembourg Institute of Science and Technology (LIST), Esch-sur-Alzette, Luxembourg, fabrice.berroir@ list.lu, orcid.org/0000-0002-0392-1011

2 R\&D Engineer, Luxembourg Institute of Science and Technology (LIST), Esch-sur-Alzette, Luxembourg, pierre.guernaccini@list.lu, orcid.org/0000-0002-5395-9042

3 Doctor, R\&D associate, Luxembourg Institute of Science and Technology (LIST), Esch-sur-Alzette, Luxembourg, calin.boje@list.lu, orcid.org/0000-0002-5150-9355

4 Managing Director, Compagnie Luxembourgeoise d'Entreprises (CLE), Capellen, Luxembourg, omar_maatar@cle.lu, orcid.org/0000-0001-6933-7873 
Instead of investing in order to properly manage and optimize material flows in early stages, it appears often easier to place responsibility on subcontractors and just let workers and site managers make do (Mossman 2008; Lafhaj and Dakhli 2018). These adversarial behaviours are even strengthened by the silo nature of the construction industry and results in wastes and time losses, notably due to repeated moving of materials (Vrijhoef and Koskela 2000; Mossman 2008; Tetik 2020).

From an environmental perspective, the construction sector is considered as one of the most polluting industries, accounting for approximately $50 \%$ of greenhouse gas production in the UK (Dadhich 2015), and a significant cause of traffic congestion in urban areas. It is estimated that building materials can make up to $30 \%$ of the tons carried across cities in growing urban areas (Dablanc 2009). Accordingly, improving construction material flows is not only about productivity and profits for the stakeholders of the built environment, but also a global environmental, health and well-being issue.

In order to tackle the above challenges, this research is set to demonstrate the applicability of innovative construction supply chain management based on Just-in-Time principles using a Construction Consolidation Centre (CCC) and a Third Third-Party Logistics (TPL) model in a Luxembourg. The potential benefits of this approach are investigated through a case study on a real-life construction site. More specifically, this article investigates how consolidated logistics can lead to both economic and environmental improvements. This is achieved by estimating: (1) the cost breakdown, return on investment and potential for profit sharing, and (2) the embodied carbon and congestion reduction. Additional benefits regarding resilience in pandemic times, Lean Construction maturity and digitalisation will be discussed as well as the current limits and barriers identified towards a fully interoperable and integrated Construction Supply Chain.

\section{BACKGROUND}

Supply Chain Management (SCM) was proposed as an answer to the productivity issues observed in construction (Vrijhoef and Koskela 2000). Based on manufacturing techniques, researchers advocated for a transfer of activities from the site to the supply chain (mentioned as "role 3") and an integrated management of the supply chain and the construction site (mentioned as "role 4"). Practical solutions were developed in the literature including Just-In-Time deliveries, packaging, Kanban and logistic centres (Arbulu and Ballard 2004; Hamzeh et. Al 2007).

By adopting and implementing the proposed SCM model, several studies demonstrated its benefits. Elvfing (2010) described successful practices implemented by a Finnish contractor using a logistics centre to manage make-to-order and large make-tostock items and reported productivity gains of $20 \%$, while also indicating that the productivity increase exceeded the additional cost related to the warehouse. Mossman 2008 reported several key figures of test projects using the London Construction Consolidation Centre, such as the building rate which sits at $60 \%$ ahead of the industry benchmark, the building cost at $80 \%$ of industry benchmark, while achieving a $73 \%$ reduction in $\mathrm{CO} 2$ emissions. Despite these significant improvements, the construction industry lacks initiative to replicate and eventually generalise this paradigm across several contexts. This lack of initiative suggests a need for economical evidences acknowledged by surveys (Lafhaj and Dakhli 2018). More recent studies have been carried out with a focus on estimating additional transportation reductions (Samuelsson 2014) and on-site labour productivity improvements (Tetik 2020) while also advocating for more in depth analysis of direct and indirect costs. 
According to Eleskar 2020, there is a new and under-investigated phenomenon in the construction industry, which is referred to as Third-Party Logistics (TPL), where specialised actors take over all or parts of the logistics management as part of specialised and project specific construction logistics arrangements. These lead to productivity improvements, cost savings and increased utilisation of site assets, however, the lack of knowledge on internal costs for logistics and the fear for unrealistic fees are barriers for a wider diffusion of the model. Although some studies provide empirical data on the costs of the TPL approach (Janné 2020), these are insufficient to be able to discern if the extra costs were offset by the benefits incurred.

In order to foster transition towards more sustainability at an urban scale, there is a need to bring more awareness on the issues concerning construction logistics, as well as a need for deeper collaboration (Morel 2020). Accordingly, this paper aims to demonstrate feasibility of TPL integrating kitting and CCC services in new context, and to provide a deeper understanding of the costs and benefits breakdown for general contractor and subcontractors and of the conditions for embodied carbon reductions.

\section{METHODOLOGY}

This research describes a case study analysis conducted during the implementation of the first CCC experiment using a TPL operator and Kitting in Luxembourg as part of a collaborative research with a General Contractor (GC). The TPL agreement included all direct logistics costs and needed to be compared with traditional logistics costs. In addition, indirect costs had to be investigated for both cases. According to Josephson (2003), Non-Value-Adding activities can be identified, categorized (when/who/how) and discussed in order to estimate and tackle over costs. This approach was chosen since the logistics costs may be borne by distributors, subcontractors or main contractor and can have many indirect impacts. As, no other project available at the time of the experimentation presented enough similarities to perform a comparative analysis, data on NVA activities and delivery scenarios for both traditional and new logistics were collected on the same site and discussed in group with contractors and subcontractor. Accordingly, following methodology was applied in order to set up a commonly agreed model of costs and carbon footprint related to logistics:

1. Initial model of cost breakdown and Key Performance Indicators (KPI) definition according to state of the art;

2. Data collection on site: All kits deliveries and consumption (giving start and end dates of corresponding tasks) were monitored in a custom web-platform prototype;

3. Estimation of the delivery scenarios with a traditional model on a bi-weekly basis based on actual needs and constraints performed by GC project managers;

4. Non-value adding time measurement on a sample of traditionally managed tasks;

5. Validation of the estimates from the previous step with subcontractors and calculation of corresponding KPI (including carbon footprint, see Table 1);

6. Adapted cost breakdown for the actual case based on accounting data from the General Contractor and indirect costs (see Table 2);

7. Adapted cost estimation for the fictional "without CCC" case based on a reviewed model (see Table 2). 
Table 1: Main KPI measured and their corresponding data collection method

\begin{tabular}{|c|c|c|}
\hline KPI & Metrics & Data collection and calculation methods \\
\hline $\begin{array}{l}\text { Planning } \\
\text { Reliability }\end{array}$ & Saved days & $\begin{array}{l}\text { For each task (involved in CCC) actual task durations have } \\
\text { been measured and compared to site schedule forecasts }\end{array}$ \\
\hline Productivity & $\begin{array}{l}\text { Time spent on } \\
\text { Non value } \\
\text { adding } \\
\text { activities }\end{array}$ & $\begin{array}{l}\text { Time measurement on Non Value adding activities on tasks } \\
\text { with kitting and on comparable tasks on the same site } \\
\text { without CCC. }\end{array}$ \\
\hline & $\begin{array}{l}\text { Number of } \\
\text { deliveries }\end{array}$ & $\begin{array}{l}\text { With CCC: actual data from the web-platform (including trip } \\
\text { from supplier to CCC and from CCC to site) }\end{array}$ \\
\hline $\begin{array}{l}\text { Iransport } \\
\text { efficiency }\end{array}$ & $\begin{array}{l}\text { Filling rates } \\
\% \text { of satisfying } \\
\text { deliveries }\end{array}$ & $\begin{array}{l}\text { Without CCC: delivery constraints on site, subcontractors' } \\
\text { delivery habits and actual needs have been collected to } \\
\text { estimate a corresponding number of deliveries }\end{array}$ \\
\hline Costs & & See detailed model of cost (table 2) \\
\hline Sustainability & $\begin{array}{l}\text { Embodied } \\
\text { Carbon }\end{array}$ & $\begin{array}{l}\text { Calculated using geographical information and number of } \\
\text { transports (with CCC: actual, without CCC: estimated) }\end{array}$ \\
\hline
\end{tabular}

Table 2: Direct and indirect cost breakdown (for General Contractor and subcontractors)

\begin{tabular}{ccc}
\hline With CCC (actual case) & Without CCC (simulated case) \\
\hline & $\begin{array}{cc}\text { (A1) Actual costs observed and } \\
\text { billed including warehouse and } \\
\text { storage costs at CCC, TPL labour } \\
\text { costs for picking and packing }\end{array}$ & $\begin{array}{c}\text { (A1) Simulation of direct logistics costs if the } \\
\text { same material for the same site had been } \\
\text { managed by the subcontractors without kitting. } \\
\text { This includes transport from supplier to the site } \\
\text { material in CCC, transportation } \\
\text { and handling on site. Calculations are based } \\
\text { on simulated delivery scenarios and samples }\end{array}$ \\
$\begin{array}{c}\text { (trucks, driver...), dispatching of kits } \\
\text { at workplaces and TPL margins. }\end{array}$ & $\begin{array}{c}\text { of time measurements for similar task and } \\
\text { (Paid by GC) }\end{array}$ & $\begin{array}{c}\text { products on the same site (for instance, pipes } \\
\text { and external doors were managed by same }\end{array}$ \\
(A2) Transportation costs from & subcontractors but with traditional logistics, \\
suppliers to the CCC calculated & and thus could be used as control sample) \\
based on actual deliveries. & (Paid by SC) \\
(Paid by SC) & (P)
\end{tabular}

(B1) Management cost including software fee and manager time on purchasing and on-site inventory.

(B1) The actual times spent were directly measured along the project
(B1) Average times per order of similar tasks and products on the site, multiplied by the number of orders and deliveries estimated. (Paid by both GC and SC)

(B2) Lifting equipment costs, based on detailed site accounting per subcontractor and avoided congestion-based utilisation rates of the lifts on site. These costs may also concern subcontractors out of the tasks using the CCC (Paid by SC)

(B3) Overall days saved on planning and their value in terms of manpower (paid by SC) and overall site costs (Paid by GC)

(B4) Productivity losses (excluding direct handling cost listed in direct costs above). This includes moving and waiting times of site crews. These costs differ from B3 as they will impact crew size instead of task duration and were obtained through comparison of time measurements on a sample of tasks with and without kitting (Paid by SC) 


\section{CASE STUDY}

\section{DESCRIPTION}

This case study focuses on the construction of a $58 \mathrm{~m}$ tower in Luxembourg by the company CLE (General Contractor). The overall project budget of $€ 35 \mathrm{M}$ was planned for a 14-floor, 138-apartment building block with a total surface area of 22,000 $\mathrm{m}^{2}$. Several constraints were identified: (1) location - a recently built dense urban area, (2) site access - very limited, (3) storage capacity on site - very low, (4) schedule - tight and (5) each apartment being finished according to individual buyer choices. Due to high prices per square meter and high demand, this context is representative of current country's market. Constraints (1-4) are considered usual suspects within the context of TPL approaches (Eleskar 2020) that drove the General Contractor to investigate SCM. Constraints (1-3) led the GC to consider testing a self-operated warehouse. Kitting was proposed as solution to constraint (4). Constraint (5) was considered as the most challenging since site managers believed kitting to manage only standardized material demands. Consequently, being able to develop the right tools and demonstrate the applicability of kitting in this context were supposed to facilitate replication to more repetitive and less variable contexts. A preliminary study eliminated the self-operated option and a CCC was organized with a TPL operator accordingly. It enabled materials to be stored, repacked and dispatched in each apartment according to site needs. Specific types were chosen for experimentation: HVAC, bathtubs/showers, tile/parquets flooring, sanitary equipment and joineries (based on subcontractor's willingness to experiment new logistics). A webbased platform was specifically set up in order to define and track material kits for each planning task. Last Planner System (already implemented at earlier stages of the project) was used to collaboratively manage deliveries. Deliveries and data collection started in November 2019 and finished in July 2020.
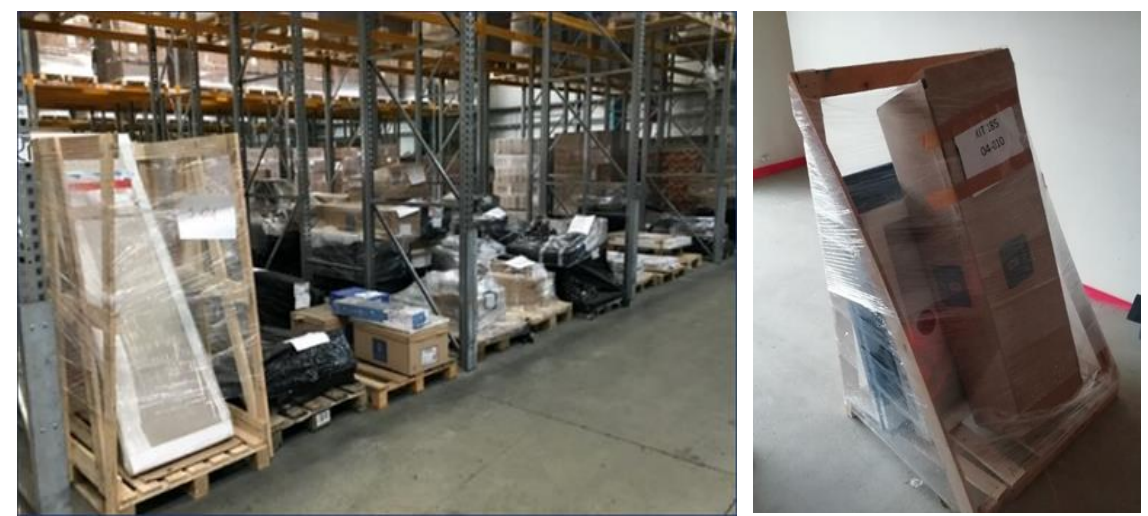

Figure 1 Example of kits at the $\mathrm{CCC}$ and after dispatch at the workspace

\section{RESULTS}

\section{Productivity and planning reliability}

According to Table 1, for each task using kitting and CCC, the actual task durations were measured and compared to initial planning duration estimated by the subcontractor before application of the new logistic system. The results are presented in Figure 2. Some task durations have been impacted by an identified external factor and thus excluded from the study (hashed boxes on the figure). The tiles tasks particularly were impacted by a 
repeated lack of labour as acknowledged by stakeholders on site. Apart from these cases, a total of 74 days was saved representing a $15 \%$ of total duration of the considered tasks.

\begin{tabular}{|c|c|c|c|c|c|c|c|c|c|c|c|c|c|c|c|}
\hline \multirow{2}{*}{ Floor } & \multicolumn{3}{|c|}{ Ventilation } & \multicolumn{3}{|c|}{ Bath/shower } & \multicolumn{3}{|c|}{ Tiles } & \multicolumn{3}{|c|}{ Sanitary equipment } & \multicolumn{3}{|c|}{ Interior Doors } \\
\hline & Planning & Reality & saved days & Planning & Reality & saved days & Planning & Reality & saved days & Planning & Reality & saved days & Planning & Reality & saved days \\
\hline 2nd Floor & 10 & 12 & -2 & 15 & 3 & 12 & 15 & & & 9 & 10 & -1 & 5 & 5 & 0 \\
\hline 3rd Floor & 10 & 6 & 4 & 10 & 6 & 4 & 15 & \multirow{10}{*}{\multicolumn{2}{|c|}{$\begin{array}{l}\text { Insufficient } \\
\text { Workforce }\end{array}$}} & 9 & 7 & 2 & 5 & 5 & 0 \\
\hline 4th Floor & 10 & 5 & 5 & 10 & 6 & 4 & 17 & & & 9 & 5 & 4 & 5 & \multicolumn{2}{|c|}{ Workforce } \\
\hline 5th Floor & 10 & 6 & 4 & 10 & 6 & 4 & 17 & & & 8 & 7 & 1 & 5 & 3 & 2 \\
\hline 6th Floor & 10 & 9 & 1 & 10 & 9 & 1 & 15 & & & 8 & 9 & -1 & 5 & \multicolumn{2}{|c|}{ no data (Covid) } \\
\hline 7th Floor & 10 & 9 & 1 & 10 & 8 & 2 & 15 & & & 8 & 9 & -1 & 5 & 2 & 3 \\
\hline 8th Floor & 10 & Work & force & 10 & 5 & 5 & 14 & & & 8 & 7 & 1 & 5 & 5 & 0 \\
\hline 9th Floor & 10 & 7 & 3 & 10 & \multirow{4}{*}{\multicolumn{2}{|c|}{$\begin{array}{l}\text { Delay due to } \\
\text { other Task } \\
\text { (Tiles) }\end{array}$}} & 15 & & & 8 & 8 & 0 & 5 & 2 & 3 \\
\hline 10th Floor & 9 & 8 & 1 & 9 & & & 15 & & & 8 & 5 & 3 & 5 & 2 & 3 \\
\hline 11th Floor & 9 & 6 & 3 & 10 & & & 15 & & & 8 & \multirow{2}{*}{\multicolumn{2}{|c|}{ no data (Covid) }} & 5 & 2 & 3 \\
\hline 12th Floor & 10 & plans & delayed & 10 & & & 9 & & & 8 & & & 5 & \multicolumn{2}{|c|}{ plans delayed } \\
\hline 13 Floor (duplex) & \multicolumn{15}{|c|}{ No Initial planning duration available } \\
\hline Total saved days & & & 20 & & & 32 & & & 0 & & & 8 & & & 14 \\
\hline
\end{tabular}

Figure 2 Gaps between planned and actual durations for tasks using kitting

Although the above results are coherent with similar cases within literature (Mossman 2008; Elving 2010; Tetik 2020), the difference may also be a result of an overestimation (consciously or not) of task durations and other positive factors may also have contributed.

To account for this, only tasks that $1^{\circ}$ were on the critical path according to weekly planning and $2^{\circ}$ were confirmed by site crews to have been impacted by kitting were kept for the calculation of overall saved days costs (B3). Moreover, the quantitative analysis was also complemented with surveys to both general contractor's team members and subcontractors (workers and supervisors). 6 out of 7 site managers expressed a light or very significant improvement in planning reliability and transparency. Similarly, $91 \%$ of workers and supervisors declared that a considerable time saving had been reached by using a CCC. The reliability of the delivery process was also directly monitored by collecting the remarks of rejected deliveries on the web-platform. In the case of the CCC, $98.5 \%$ of deliveries were performed on site as planned and at the desired time. The remaining $1.5 \%$ were mainly due to upstream errors detected and reported soon enough by the operator to mitigate their impact on-site.

\section{Total cumulated costs}

Demonstrating the economic impact of the implementation of the CCC is a complex task. While the invoiced costs related to CCC are known explicitly, they replace traditional costs that are usually confidential and difficult to measure by nature because of the specificity of each construction project. The results announced below are therefore hypothetical. The overall costs measured and calculated are presented in Figure 3 according to the model of costs presented Table 2. An unexpected cost is mentioned in the "with CCC" section and describes the impact of the costs related to the Covid-19 crisis, which overlapped with the case study time span. This is since some storage costs continued to be billed during the shutdown of production due to the lockdown in April 2020. These costs have been integrated in the final model for actual costs. However, the impact of the pandemic on estimated cost with a traditional logistic scheme could not be modelled. Overall, the estimates show a $9.5 \%$ increase in direct logistic costs (and 15\% if Covid costs are considered). This is coherent with the state of the art as TPL (Eleskar 2020) or kitting (Tetik 2020) adds additional billed services such as warehouse costs or preparation costs. Direct costs, although "visible one", account for a minority share of the overall costs according to the estimations. The total calculated impact of logistics accounted for $\sim 13.3 \%$ of the turnover of the lots considered. Thanks to kitting and TPL, this figure was decreased by up to $39 \%$, down to $8.1 \%$. This would mean a potential $2.4 \%$ 
(without considering planning indirect impacts on planning B3) to 5.2\% (with B3) margin increase for the specific lots/types of objects with kitting.

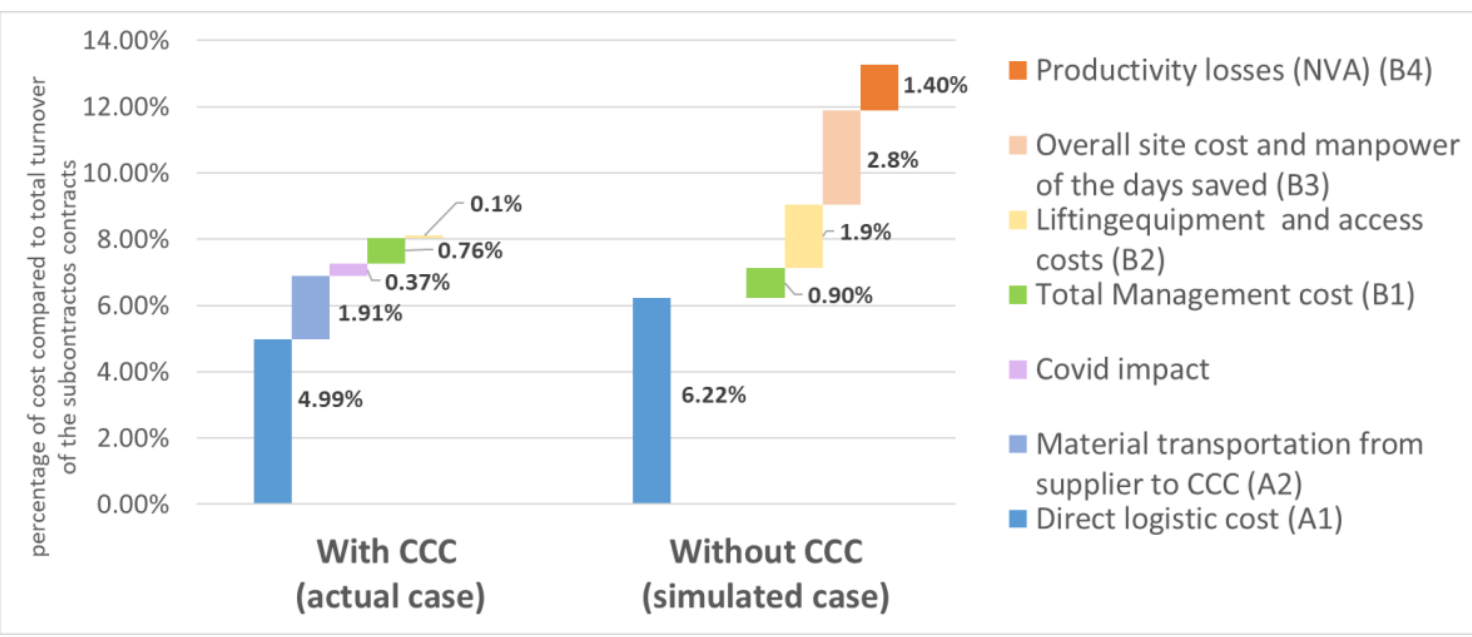

Figure 3 Overall costs breakdown in percentage of the total turnover of the lots studied

The TPL approach has also caused a shift in the distribution of costs between project stakeholders. If the GC paid the totality of the TPL agreement, the total costs related to logistics for the GC would increase from $1.9 \%$ with the traditional model to $6.1 \%$ of the considered tasks turnover, whereas the corresponding cost for subcontractors would decrease from $11.4 \%$ to $1.9 \%$.

\section{Transport, congestion and carbon footprint}

With 138 apartments on 12 floors, it was estimated that 144 deliveries (for 744 pallets) would have been performed without CCC. This estimation has been established considering the constraints observed such as storage area, delivery rate, availability of the lift, available workforce and usual transportation mean used by subcontractors or by their supplier on a weekly basis.

The data management platform set up for the project offered the possibility to collect the totality of delivery vehicles' contents and track the resulting filling rates. As a result, 49 deliveries were made to the construction site and 96 deliveries were made from the supplier to the CCC. This means an overall reduction in transport arriving on site by $66 \%$.

Filling rates measured exceed $80 \%$ on average, except during the month of April which was strongly impacted by disturbances due to the Covid-19 sanitary crisis and certain special contexts (notably during holiday periods).

Knowing locations of the CCC and suppliers/subcontractors' facilities and each usual transportation means, it was possible to calculate the carbon footprint of deliveries with the consolidated logistics method, for both scenarios according to EN 16258 (2012). These estimates show an overall $46 \%$ reduction in carbon emissions for transports compared to traditional logistics (see Figure 4).

\begin{tabular}{|cccc|}
\hline Task & With CCC & Without CCC & Impact \\
\hline Ventilation & 10.12 & 10.4 & $-2.69 \%$ \\
\hline Bath/Shower & 0.61 & 0.8 & $-23.75 \%$ \\
\hline Sanitary equipment & 0.64 & 0.6 & $+6.7 \%$ \\
\hline Tiles & 3.79 & 1.9 & $+99.5 \%$ \\
\hline Doors & 10.91 & 34.2 & -0.68 \\
\hline Total (in T of CO2) & $\mathbf{2 6}$ & $\mathbf{4 8}$ & $-\mathbf{4 6} \%$ \\
\hline
\end{tabular}

Figure 4 - Total $\mathrm{CO} 2$ emissions in tons for transports 


\section{DISCUSSION}

\section{Impact on project management and Lean construction maturity}

Beyond a flat reduction of management costs (B1), the measures reveal a change in the site's management practices. Contingency management, reception of delivery vehicles and inventory tasks were normalised over the week and mostly replaced by anticipation tasks. This was considered as a driver for better collaboration on site, while also offering a clear framework for recently hired managers to get more responsibilities and skills. This improvement in collaboration was also confirmed by qualitative feedbacks from subcontractors about the use of Last Planner System (LPS). Although kitting and TPL could have been managed without the LPS, the collaborative framework of LPS facilitated the gathering of the actual material needs and constraints. On the other hand, having a reliable and constantly updated view of material status enabled to start weekly meeting with a trusted workable backlog. These findings are further arguments in favour of the development of a holistic Lean Construction approach.

\section{TPL viability and gain sharing}

In order to validate the TPL choice, a GC self-operated warehouse scenario was modelled under the same hypothesis. It concluded that direct logistic costs (A1) would have been double compared to actual case with TPL. In comparison with TPL, self-operated centralised logistic requires existing facilities and a higher volume of activities in order to be relevant and applicable in the considered context.

With TPL, a potential 5\% overall margin gain was estimated, but this gain must be shared between stakeholders to ensure its applicability. Indeed, the TPL model as implemented in this study was driven and financed by the General Contractor, but it appears to mostly benefit the subcontractors. In the context of this project, a total $3.6 \%$ price cut was negotiated between stakeholders, which covered $72 \%$ of the costs of TPL.

According the results of this case study, a contribution of approximately 5\% from the turnover would cover all the direct costs endorsed by the General Contractor while maintaining a $4.4 \%$ margin increase for the subcontractors.

\section{Covid-19 and co-activity reduction}

Covid-19 negatively impacted the costs results of the case study because of unexpected storage costs. However, qualitative feedbacks also indicate some potential advantages of kitting and CCC to deal with similar unexpected situations. This is acknowledged by planning reliability measures indicating that with the workflow being streamlined, kitting reduced co-activity. Additionally, the CCC worked as a buffer for materials during the lockdown. This may be one of the reasons why the site had nearly fully recovered its normal productivity rates in May (which according to the GC was not the case in most of its other projects) suggesting that CCC could improve the sector's resilience.

\section{LIMITATIONS AND FUTURE RESEARCH}

This research was limited to one pilot case study in order to test feasibility in a new context and to perform an in-depth analysis of costs and impacts on site of the new logistics model. Productivity and planning gains were particularly hard to assess as other factors may have contributed to improved performance. More studies are needed to confirm the model of cost proposed and to validate the authors' findings. Two key points of interest are highlighted by this study. 


\section{And Kitting SustainabiLity Assessment}

The findings of this study indicate that CCC and kitting can be used as an efficient strategy in order to reduce embodied carbon. However, Figure 5 shows discrepancies on the carbon emissions reduction achieved in the study. For example, the model was not relevant for some suppliers that were located closer to the site. This shows that under certain circumstances the model might not be optimal. Defining these conditions and being able to integrate them into projected simulations would enable better sustainability and better estimations of the impacts. In addition, kitting enabled better productivity on site through better resource efficiency (mainly of workers and lifting capacity) that might also have a positive environmental impact, but these impacts still must be assessed.

\section{Digital Twin fOR InTEgrated SuPPly Chain MANAgement}

The new logistics organisation implied a transfer of responsibility and hence an extended knowledge of the products to be delivered as well as full traceability of the materials condition. To achieve this, an online platform had been set up that enabled to define custom kits for each task and manage event or relevant status. This information system appeared to be a key factor to a successful implementation. However, most information had to be entered manually and was in a format that could not allow further use of the data. Therefore, data should be structured, interoperable and dynamic in a way that it allows collaboration and transfer along the supply chain and support decision-making. As a solution, the emerging research on Digital Twin (Boje et al. 2020) and application of Products Data Templates (ISO 23386 and EN ISO 23387) appear as key research topics.

\section{CONCLUSION}

This paper investigated the potential for innovative Supply Chain Management based on Lean Management techniques to be an economically relevant paradigm that can help reduce the carbon footprint of the sector. The pilot project in Luxembourg successfully implemented Just-In-Time logistics using kitting and a Construction Consolidation Centre managed by a Third-Party Logistics operator. Despite the fact that the empirical results were limited in scope, they confirm both the economic and environmental improvements due to these methods by enabling at the same time up to $39 \%$ reduction of logistics related costs - that would mean a $5 \%$ potential margin increase for the considered tasks, and a $46 \%$ reduction of carbon emissions. These findings are preliminary as this project was the first of its kind in the country and some other factors may have interfered and should be further investigated (especially regarding the impact on planning). Additional improvements through new services such as reverse logistics and multi-site deliveries should also be considered and tested. The study emphasizes three potential barriers that need to be addressed. Firstly, the model of costs developed through the project estimated that logistics and material handling would have accounted for at least $13 \%$ of the turnovers of the lots if managed in a traditional way. More data on the implications of these costs are necessary to raise sector's awareness and interest in newer methods. Secondly, the environmental impacts must be further studied to ensure case-bycase improvements. Lastly, the kitting required detailed information about planning and actual material status and constraints that should be addressed through collaborative practices on site and digitally supported integration of the supply chain. 


\section{REFERENCES}

Arbulu, R., and Ballard, G. (2004). "Lean Supply Systems in Construction" 12th Annual Conference of the International Group for Lean Construction. Helsingør, Denmark, pp 1-13.

Boje, C., Guerriero, A., Kubicki, S., and Rezgui, Y. (2020). "Towards a semantic Construction Digital Twin: Directions for future research" Automation in Construction, 114, 103179.

Dablanc, L., (2009). "Freight transport for development toolkit: urban freight" (No. 57971). The World Bank, 1818 H Street NW, Washington, DC 20433.

Dadhich, P., Genovese, A., Kumar, N., and Acquaye, A. (2015). "Developing sustainable supply chains in the UK construction industry: A case study", International Journal of Production Economics Vol. 164, pp. 271-284.

Dakhli, Z., and Lafhaj, Z. (2018). "Considering Materials Management in Construction: An Exploratory Study." Logistics. 2(1):7. doi.org/10.3390/logistics2010007.

Ekeskär, A., and Rudberg, M. (2020). "Third-party logistics in construction: perspectives from suppliers and transport service providers." Production Planning \& Control, 0(0), 1-16. doi.org/10.1080/09537287.2020.1837932.

Elfving, J. A. , Ballard, G. and Talvitie, U. (2010). "Standardizing Logistics at the Corporate Level Towards Lean Logistics in Construction" 18th Annual Conf. of the International Group for Lean Construction. Haifa, Israel, 14-16 Jul 2010. pp 222-231.

Hamzeh, F. R. , Tommelein, I. D. , Ballard, G. and Kaminsky, P. M. (2007). "Logistics Centers to Support Project-Based Production in the Construction Industry" 15th Annual Conference of the International Group for Lean Construction. East Lansing, Michigan, USA, 18-20 Jul 2007. pp 181-191.

Josephson, P. \& Saukkoriipi, L. (2003). "Non Value-Adding Activities in Building Projects: A Preliminary Categorization" 11th Annual Conference of the International Group for Lean Construction. Virginia, USA.

Janné, M., and Rudberg, M. (2020). "Effects of employing third-party logistics arrangements in construction projects." Production Planning \& Control, 0(0), 1-13. doi.org/10.1080/09537287.2020.1821925.

Mossman, A. (2008) "More than materials: managing what's needed to create value in construction." 2nd European Conference on Construction Logistics - ECCL, Dortmund, May 08.

Samuelsson, S., and Ahmetasevic, M. (2014). "Management of construction logistics in Stockholm: Identifying ways of improvement for construction logistics within the inner city of Stockholm" (Dissertation). Retrieved from http://uu.divaportal.org/smash/record.jsf?pid=diva2\%3A733476\&dswid=-4129.

Tetik, M., Peltokorpi, A., Seppänen, O., Leväniemi, M., and Holmström, J. (2021). "Kitting Logistics Solution for Improving On-Site Work Performance in Construction Projects." Journal of Construction Engineering and Management, 147(1), 05020020.

Vrijhoef R. and Koskela L. (2000). "The four roles of supply chain management in construction”, European Journal of Purchasing \& Supply Management, Vol 6, pp. 169-178. 